\title{
Erasme de Rotterdam, La Formation du prince chrétien. Institutio principis christiani
}

\section{Michele Mastroianni}

\section{(2) OpenEdition}

1 Journals

\section{Edizione digitale}

URL: http://journals.openedition.org/studifrancesi/5280

DOI: 10.4000/studifrancesi.5280

ISSN: 2421-5856

\section{Editore}

Rosenberg \& Sellier

\section{Edizione cartacea}

Data di pubblicazione: 1 dicembre 2016

Paginazione: 515

ISSN: 0039-2944

\section{Notizia bibliografica digitale}

Michele Mastroianni, «Erasme de Rotterdam, La Formation du prince chrétien. Institutio principis christiani », Studi Francesi [Online], 180 (LX | III) | 2016, online dal 01 janvier 2017, consultato il 18 septembre 2020. URL : http://journals.openedition.org/studifrancesi/5280 ; DOI : https://doi.org/ 10.4000/studifrancesi.5280

Questo documento è stato generato automaticamente il 18 settembre 2020.

\section{(c) 9 (i) $\Theta$}

Studi Francesi è distribuita con Licenza Creative Commons Attribuzione - Non commerciale - Non opere derivate 4.0 Internazionale. 


\title{
Erasme de Rotterdam, La Formation du prince chrétien. Institutio principis christiani
}

\author{
Michele Mastroianni
}

\section{NOTIZIA}

ERASME DE ROTTERDAM, La Formation du prince chrétien. Institutio principis christiani, édition de Mario Turchetti, Paris, Classiques Garnier, 2015, 446 pp.

1 Se fino a questo momento gli studiosi del Rinascimento, non solo gli specialisti di Erasmo, potevano annoverare fra le traduzioni delle opere del grande umanista una versione dell'Institutio in inglese di M.J. Heath (Cambridge University Press, 1997'; $2007^{2}$ ), una versione in olandese di J. De Landtsheer (Amsterdam, Athenaeum-Polak \& Van Gennep, 2005) e una versione in italiano di D. Canfora (Bari, Edizione di Pagina, 2009), oggi possono disporre anche della traduzione francese di M. Turchetti che non si limita a un accurato lavoro di trasposizione idiomatica ma introduce, contestualizza e discute questo scritto erasmiano, pubblicato nel 1518, con uno studio puntuale che si impone come vero e proprio saggio (110 pp.), poiché ricco di informazioni storiche, di spunti e analisi filologicamente utili e precise, di interpretazioni convincenti sul pensiero di Erasmo, in particolare sull'ideologia che il noto umanista sviluppa, nella sua Institutio, sulla nozione di pace e su quella opposta di guerra, ma soprattutto sul concetto di potere politico dei Principi fra Umanesimo e Rinascimento (Erasmo si rivolge al giovane Carlo di Borgogna, futuro Carlo V, e a Papa Leone X). L'intento di Turchetti, sotto un profilo storiografico, quanto in prospettiva metodologica, è chiaro. Egli dichiara da subito che «le lecteur qui entend étudier [1]es œuvres [d'Érasme] - l' Institutio en particulier-dans le respect du sens historique et dans le souci de comprendre la pensée de l'auteur, doit éviter deux écueils: d'une part la tentation de relier d'une manière quelconque ce texte à la reforme luthérienne qui est proche, mais encore absente de l'univers éramien; de l'autre, la tentation de rapprocher la pensée 
d'Érasme de celle de Machiavel. Ce dernier a certes déjà rédigé Il Principe, mais ne l'a pas encore publié. Cette œuvre semble alors inconnue de l'humaniste néerlandais et absente de son monde intellectuel». Se quindi Turchetti precisa, da un lato, l'estraneità della riforma luterana e dell'influsso di Machiavelli sull'Institutio, dall'altro sottolinea invece il ruolo decisivo del cardinale tedesco Nicola Cusano sull'ideologia pacifista di Erasmo, insistendo soprattutto su due nozioni, filosofiche e teologiche a un tempo, che avrebbero determinato la costruzione del pensiero erasmiano sul concetto di pace. $\mathrm{Si}$ tratterebbe della concordia fra Principi cristiani e della tolleranza degli stessi di fronte all'avanzata del potere turco che Erasmo, perseguendo la difesa della christiana pax e della Respublica christiana, vorrebbe piegare pacificamente a conversione attraverso un mirato esercizio di evangelizzazione. Prendendo ispirazione, in particolare, da Isocrate e da Plutarco, soprattutto da Isocrate, ma anche da Platone e Aristotele, Erasmo, nella sua Institutio, coniuga discorso morale e discorso politico, secondo un principio di attualizzazione storica necessario alla istruzione e alla formazione di Carlo V, finalizzata alla responsabilità politica, giuridica e civile, ma centrata sull'amore di Cristo. Su questo punto - come sottolinea giustamente Turchetti - si crea lo spartiacque fra i trattati sulla formazione del Principe nell'antichità e l'Institutio: scritto politico che insiste su alcune necessarie virtù del Principe come la prudenza, la temperanza e l'integrità morale.

2 Si segnala quindi questa edizione utile per la chiara ricostruzione delle fonti che sottostanno alla filosofia di Erasmo, in particolare all'Institutio, opera ideologicamente interessante anche per gli evidenti richiami alla tradizione antica. 